\title{
Investigating the Effect of a Structured Intervention on the Development of Self-Care Behaviors With Arteriovenous Fistula in Hemodialysis Patients
}

\author{
Clemente Neves Sousa, PhD ${ }^{1,2}$, Ana Rita Cabral Paquete, MmsN³ \\ Paulo Teles, $\mathrm{PhD}^{4}$, Cristina Maria Correia Barroso Pinto, PhD ${ }^{1,2}$, \\ Vanessa Filipa Ferreira Dias, MPH ${ }^{5,6}$, Olga Maria Pimenta Lopes Ribeiro, PhD ${ }^{1,2}$, \\ Carlene Souza Silva Manzini, PhD ${ }^{7}$, Andressa Garcia Nicole, PhD ${ }^{8}$, \\ Lara Helk Souza, PhD', and Nurten Ozen, PhD ${ }^{10}$
}

\begin{abstract}
This study aimed to assess the effectiveness of a structured intervention on the frequency of self-care behaviors with arteriovenous fistula (AVF) by patients on hemodialysis. This is a quasi-experimental study with pre- and post-measurements. Participants were assigned to an intervention group (IG) $(n=48)$ or to a control group $(C G)(n=4 I)$. IG patients were subject to a structured intervention on self-care with AVF (SISC-AVF) consisting of both a theoretical and a practical part. After SISC-AVF application, patients in the IG showed better overall self-care behaviors with AVF than patients in the CG (79.2\% and $91.4 \%$, respectively, $p<.00 \mathrm{I})$ as well as better self-care concerning both the management of signs and symptoms $(90.1 \%$ and $94.4 \%$ respectively, $p=.004)$ and the prevention of complications $(72.7 \%$ and $89.5 \%$, respectively, $p<.00 \mathrm{I})$. The study results suggest that the SISC-AVF had positive effects on patients in the IG.
\end{abstract}

\section{Keywords}

hemodialysis, self-care, patient education, arteriovenous fistula, vascular access

\section{Introduction}

End-stage kidney disease (ESRD) is a public health problem in developed or developing countries, especially in the United States, Europe, Brazil, and in some countries in Asia (Enrica \& Manjula Kurella, 2016; Clementi et al., 2020). Portugal is among the European countries with the highest incidence and prevalence of ESRD with 235.9 and 1577.9 per million population (pmp) in 2010, and 226.49 and $1661.9 \mathrm{pmp}$ in 2011 (Coelho et al., 2014; Clementi et al., 2020). Patients with this disease need a vascular access to undergo hemodialysis (HD) treatment.

The scientific community considers the arteriovenous fistula (AVF) as the best vascular access for HD when compared with other access types (graft and central venous catheter). Prior studies have reported that central venous catheters and arteriovenous grafts are associated with a higher risk of mortality in HD patients than the AVF (NKF-K/DOQI, 2006; Tordoir et al., 2007; Kukita et al.,
'CINTESIS - Center for Health Technology and Services Research Faculty of Medicine, Porto University, Porto, Portugal

${ }^{2}$ Nursing School of Porto, Porto, Portugal

${ }^{3}$ Dialysis Unit to Hospital Divino Espirito Santo, Ponta Delgada, Açores, Portugal

${ }^{4}$ School of Economics, University of Porto and LIAAD-INESC Porto LA, Porto, Portugal

${ }^{5}$ Institute of Health Sciences, Católica University, Lisbon, Portugal

'Unidade de Saúde Familiar St. André de Canidelo, Vila Nova de Gaia,

Porto, Portugal

${ }^{7}$ São Carlos Federal University (UFSCar), São Carlos, Brazil

${ }^{8}$ Federal University of Espírito Santo, Espírito Santo, Brazil

${ }^{9}$ Faculdade Medicina São José Rio Preto (FAMERP), São josé do Rio Preto, Brazil

${ }^{10}$ Florence Nightingale Hospital School of Nursing, Demiroglu Bilim University, Istanbul, Turkey

\section{Corresponding Author:}

Clemente Neves Sousa, PhD, Nursing School of Porto, Rua Dr. António Bernardino de Almeida, Porto 4200-072, Portugal.

Email: clementesousa@esenf.pt 
2015; Ibeas et al., 2017). Furthermore, the AVF is less prone to complications and thromboses than central venous catheters and arteriovenous grafts (Ibeas et al., 2017). Dialysis teams (nephrologist, dialysis nurse, and vascular access nurse) are required to educate patients on how to appropriately carry out self-care behaviors concerning access maintenance and preservation (Wingard, 2005; Moist et al., 2013).

Several guidelines recommend that patients with ESRD should be educated on how to take care of their own AVF (NKF-K/DOQI, 2006; Tordoir et al., 2007; Kukita et al., 2015; Ibeas et al., 2017; Schmidli et al., 2018). Some studies have shown that patients generally do not carry out those behaviors required to prevent infection of the AVF, preserve its functioning and identify signs and symptoms of distal hypoperfusion (Pessoa \& Linhares, 2015; Ozen et al., 2017; Sousa et al., 2017, 2020; Teixeira et al., 2017). Furthermore, a number of studies have also shown that patients have little or almost no knowledge on AVF care and, in fact, the proportion of such patients can reach nearly 98\% (Pessoa \& Linhares, 2015).

The literature describes very accurately those behaviors that must be taught by dialysis teams to promote self-care (NKF-K/DOQI, 2006; Sousa, 2012; Ibeas et al., 2017; Sousa et al., 2014, 2017). Dialysis units should design educational programs to empower patients for self-care behaviors (Trask et al., 2016), especially concerning infection and thrombosis.

A few articles only are available in the literature on selfcare behaviors with AVF and there is virtually no information on the type of interventions that can be used in educational programs whose purpose is empowering patients for care with AVF (Sousa et al., 2014; Pessoa et al., 2020). Some studies propose theoretical lecturing as a possible intervention in this context (Sousa et al., 2014) but do not explain how such intervention should be carried out. The identification of the most effective interventions on self-care behaviors with $\mathrm{AVF}$ and of unsuitable interventions for patients is required. The aim of this study was assessing the effectiveness of a structured intervention on the frequency of self-care behaviors with AVF in patients with ESRD on regular HD programs.

\section{Methods}

\section{Study Design and Setting}

This was a quasi-experimental study in dialysis units, involving patients on HD using AVF. The dialysis units are located in the north of Portugal (two units) and in the Autonomous Region of the Azores (one unit). Patients located in the north of Portugal and in the Azores were assigned to the Control Group (CG) and to the Intervention Group (IG) respectively. Random sampling was the method used and the allocation of the dialysis units to the groups was intentional, for reasons of convenience of the research team.
Participants' eligibility criteria for the study were as follows: participants should be 18 years or older, on HD with AVF for a period of more than 6 months, have no memory problems and be medically stable. The exclusion criteria were: patients with double vascular access (central venous catheter and AVF) or grafts as vascular access and hospitalized patients at the time of data collection. Participants were invited for the study. Those with no interpretation problems completed the questionnaire autonomously whereas those who had trouble to understand it or suffered from vision impairment were assisted by the researcher. The population size was 177 patients and 89 participants were included in the study after application of the criteria (Figure 1).

\section{Data Collection and Instrument}

All data were collected between January and February 2018. Data concerning the sample demographic characteristics (age, gender, education, employment, marital status) and clinical characteristics (ESRD etiology, dialysis vintage, previous AVFs, AVF duration, information on care with AVF) were collected with a questionnaire designed by the authors.

Information concerning self-care behaviors with AVF was collected from the Scale of Assessment of Self-Care Behaviors with Arteriovenous Fistula in Hemodialysis (ASBHD-AVF) (Sousa et al., 2015). This scale has 16 items in two self-care subscales: Management of Signs and Symptoms (6 items) and Prevention of Complications (10 items). Responses to each item are based on a 5-point Likerttype scale. Higher scores show patients' higher frequency of self-care with AVF. The ASBHD-AVF scale was applied to Portuguese patients with Cronbach's alpha of .797, .797, and .722 for the overall scale and the two subscales mentioned above respectively. Memory problems were assessed by the Six-Item Cognitive Impairment Test (6CIT), Portuguese version (Apóstolo et al., 2017).

\section{Intervention Protocol: Structured Intervention for Self-Care With AVF}

The intervention concerning self-care with the AVF (SISCAVF) was carried out based on the structure of Sousa (2012) which enables nurses to train patients for self-care and for the development of instrumental skills required for surveillance of the AVF.

The structured intervention designed for this study was a multimethod approach with the purpose of capturing the learning styles of most patients through the use of written, listening, and visual learning (Kitchie, 2016). The SISCAVF had the purpose of identifying the signs/symptoms or situations jeopardizing AVF working and includes both a theoretical and a practical part. The relationship between Sousa's structure (Sousa, 2012) and SISC-AVF is displayed in Figure 2. 


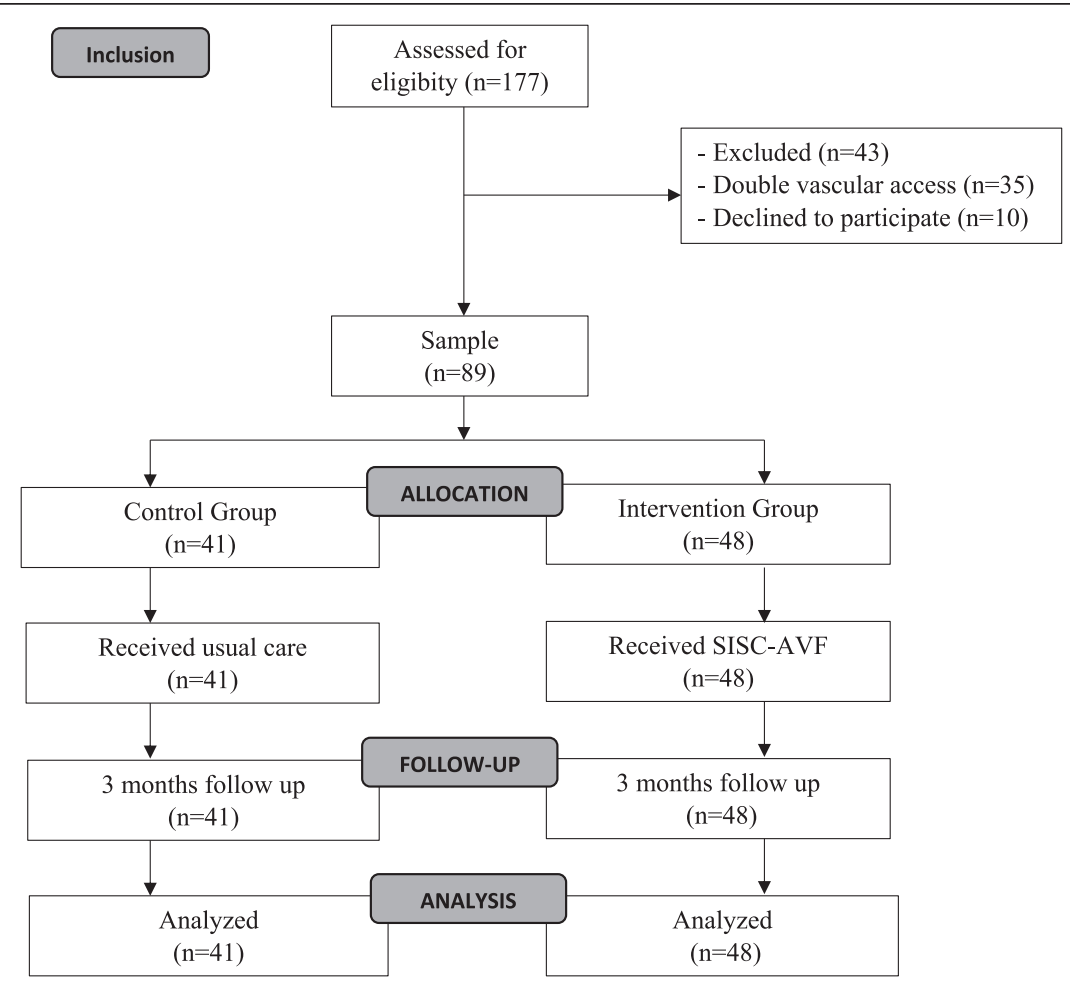

Figure I. Participant flow diagram.

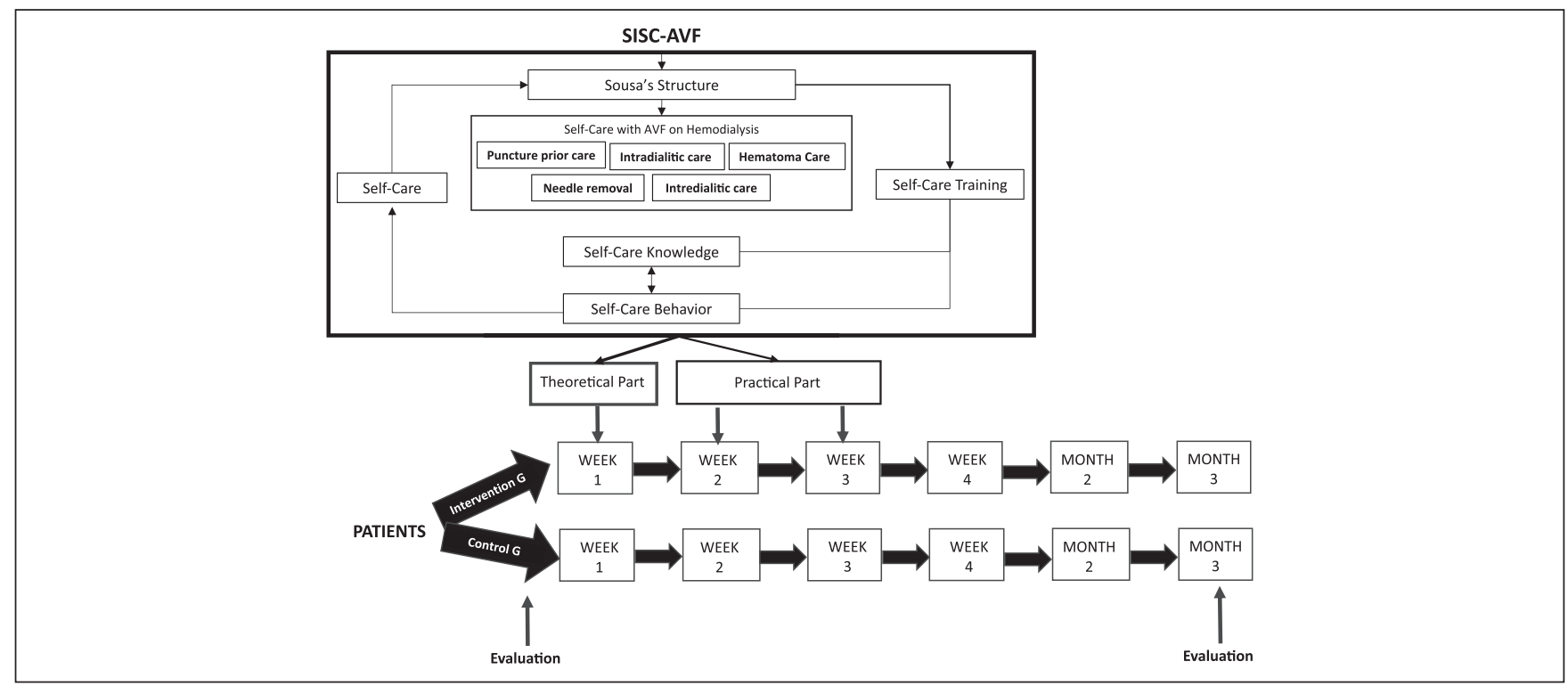

Figure 2. Monitoring of the intervention group.

\section{SISC-AVF: Theoretical Part}

The theoretical part of this structured intervention involved an educational group session called "Care with AVF" with the purpose of teaching patients how to identify situations that can compromise AVF working. The session, presented by the researcher to all study participants, included six presentations held in an appropriate room for 2 days before patients started HD treatment. Each presentation allowed a maximum of eight patients and took $30 \mathrm{~min}$. The lecturing-participating method was selected for this part, encouraging participants' interactivity. The session's theoretical assumptions, described 
in Sousa (2012) were included in the presentation of the following topics: AVF general concepts; AVF importance for ESRD patients; AVF functionality; prevention and detection of signs and symptoms of infection, thrombosis and steal syndrome. Each presentation was assessed in the end by asking participants to identify the signs and symptoms of infection, thrombosis and steal syndrome and to describe the care to be taken during dialysis and in the period outside dialysis.

\section{SISC-AVF: Practical Part}

The SISC-AVF practical part started a week after the theoretical part, lasted 2 weeks and was provided to each participant in an appropriate room at the beginning of the HD treatment. Interactive training sessions were conducted using an informal approach with the objective of developing skills of inspection and palpation of the AVF arm. Inspection had the purpose of enabling participants to identify situations that could compromise AVF working. They were also trained to recognize AVF working by palpation. Each patient was given two 15-min sessions. Participants were given an information leaflet on the care to be taken with the AVF in the end of the SISC-AVF.

\section{Usual Care Control}

Educational training was given during HD sessions. The dialysis nurse provided information on AVF care and trained patients whenever they felt such need. Such information was handed out occasionally, without a plan, and no assessment was ever made. Based on his/her perception of the information requirements, the dialysis nurse decided when training was provided. Dialysis units had no documentation concerning the educational training given to patients and the moments to provide such information were not defined.

\section{Statistical Analysis}

Quantitative variables were described by the minimum, maximum, mean, median, quartiles, and standard deviation $(S D)$. The distribution of categorical variables was described by proportions. Comparisons between the two groups (independent samples) were made by the Chi-Square Test for categorical variables and by the Mann-Whitney Test for quantitative variables, whereas pre- and post-intervention comparisons for each group were made by the Wilcoxon Test for paired samples ( $5 \%$ significance level). Analysis was performed with the Statistical Package for the Social Sciences Software (version 26.0; IBM Co., USA) and with the R language (version 3.6.3, R Foundation for Statistical Computing, Austria). In statistical decisions, $p<.05$ was considered statistically significant.

\section{Ethical Considerations}

All participants were protected from physical and psychological injury and retained their right to privacy and to informed consent, according to the Declaration of Helsinki. The study started after approval by the institutions' ethics committees. All participants signed an informed consent at the moment of inclusion in the study.

\section{Results}

\section{Patient Characteristics}

The study involved 89 patients with AVF (41 and 48 patients in the CG and IG, respectively). No statistically significant differences were found between the CG and the IG concerning demographic and clinical variables other than age, employment, and information on AVF care (Table 1). Therefore, with the exception of these three variables, both groups had similar demographic characteristics. Patients in the CG were older than those in the IG (average of 65.8years and 58.7years, respectively, $p=.013$ ). Concerning employment, most patients in the CG and half of those in the IG were retired $(85.4 \%$ and $50.0 \%$, respectively, $p=.003$ ). Finally, information on AVF care was provided by the nurse to $48.8 \%$ and $77.1 \%$ of the CG and IG patients, respectively and by the nephrologist to $51.2 \%$ and $20.8 \%$ of those patients respectively $(p=.011)$, that is, information was provided by nurses to a larger proportion of patients in the IG and by nephrologists in the CG.

\section{Intervention Effect on Self-Care Behaviors With AVF}

Implementation of the SISC-AVF had a very positive effect on patients in the IG. In fact, they showed better results than patients in the CG concerning the overall self-care behaviors with AVF $(79.2 \%$ and $91.4 \%$, respectively, $p<.001)$, the self-care subscale of signs and symptoms management ( $90.1 \%$ and $94.4 \%$, respectively, $p=.004)$ and the self-care subscale of prevention of complications $(72.7 \%$ and $89.5 \%$, respectively, $p<.001$ ).

Furthermore, the IG self-care behavior minimum and maximum values increased after the SISC-AVF both for the overall scale and the self-care subscales: from $34.4 \%$ to $68.8 \%$ and from $95.3 \%$ to $100 \%$, respectively for the scale; from $16.7 \%$ to $58.3 \%$ and staying equal to $100 \%$ in both periods respectively for the subscale of signs and symptoms management; and from $42.5 \%$ to $70 \%$ and from $97.5 \%$ to $100 \%$, respectively for the subscale of prevention of complications.

Therefore, the SISC-AVF led to a statistically significant increase of average self-care behaviors with AVF in the IG, both for the overall scale and for the two self-care subscales (Table 3). On the contrary, pre- and post-intervention average self-care behaviors are approximately the same for the overall scale and the subscales in the CG, leading to a nonsignificant difference.

During follow-up (3 months), one patient had an AVF infection and another had a thrombosis in the CG. No AVF infection or thrombosis were reported in the IG. 
Table I. Pre-Intervention Demographic Baseline Characterization.

\begin{tabular}{|c|c|c|c|c|}
\hline & Overall $(n=89)$ & CG $(n=4 I)$ & IG $(n=48)$ & $p$-value \\
\hline Gender (M/F) (\%) & $65.2 / 34.8$ & $65.9 / 34.1$ & $64.6 / 35.4$ & $>.999$ \\
\hline Age, years (mean; SD) & $62.0 ; 13.9$ & $65.8 ; 12.5$ & $58.7 ; 14.3$ & .013 \\
\hline Education (\%) & & & & .248 \\
\hline None & 4.5 & 4.9 & 4.2 & \\
\hline$\leq 4$ years & 48.3 & 53.7 & 43.8 & \\
\hline 5-6years & 13.5 & 4.9 & 20.8 & \\
\hline 7-9years & 14.6 & 14.6 & 14.6 & \\
\hline $10-12$ years & 12.4 & 14.6 & 10.4 & \\
\hline College & 6.7 & 7.3 & 6.3 & \\
\hline Employment (\%) & & & & .003 \\
\hline Self-employed & 2.2 & 0.0 & 4.2 & \\
\hline Employee & 9.0 & 7.3 & 10.4 & \\
\hline Unemployed & 21.3 & 7.3 & 33.3 & \\
\hline Retired & 66.3 & 85.4 & 50.0 & \\
\hline Student & 1.1 & 0.0 & 2.1 & \\
\hline Marital status (\%) & & & & .561 \\
\hline Married & 65.2 & 65.9 & 64.6 & \\
\hline Non-martial partnership & 3.4 & 2.4 & 4.2 & \\
\hline Divorced & 7.9 & 9.8 & 6.3 & \\
\hline Single & 12.4 & 7.3 & 16.7 & \\
\hline Widow & 11.2 & 14.6 & 8.3 & \\
\hline ESRD ethiology (\%) & & & & .407 \\
\hline Diabetic nephropathy & 32.6 & 26.8 & 37.5 & \\
\hline Hypertension & 15.7 & 12.2 & 18.8 & \\
\hline \multicolumn{5}{|l|}{ Glomerulonephritis } \\
\hline Unknown & 24.7 & 34.1 & 16.7 & \\
\hline Dialysis vintage (\%) & & & & .218 \\
\hline$<$ I year & 21.3 & 14.6 & 27.1 & \\
\hline I year-5years & 37.1 & 39.0 & 35.4 & \\
\hline$>5$ years & 41.6 & 46.3 & 37.5 & \\
\hline AVF duration (months) (mean; SD) & $51.0 ; 52.3$ & $58.0 ; 59.1$ & $45.0 ; 45.6$ & .184 \\
\hline AVF complications (\%) & 25.8 & 24.4 & 27.1 & .963 \\
\hline Thrombosis & 52.2 & 50.0 & 53.8 & \\
\hline Infection & 8.7 & 0.0 & 15.4 & \\
\hline Hemorrhage & 13.0 & 0.0 & 23.1 & \\
\hline Aneurysm & 8.7 & 20.0 & 0.0 & \\
\hline Other & 17.4 & 30.0 & 7.7 & \\
\hline Number previous AVFs (\%) & & & & .453 \\
\hline I & 74.4 & 35.9 & 78.9 & \\
\hline 2 & 7.7 & 2.6 & 10.5 & \\
\hline 3 & 7.7 & 5.1 & 5.3 & \\
\hline$\geq 4$ & 10.3 & 7.7 & 5.3 & \\
\hline Information on the AVF (\%) & & & & .011 \\
\hline Doctor & 1.1 & 0.0 & 2.1 & \\
\hline Nephrologist & 34.8 & 51.2 & 20.8 & \\
\hline Nurse & 64.0 & 48.8 & 77.1 & \\
\hline
\end{tabular}

Note. $\mathrm{CG}=$ control group; IG = intervention Group; $\mathrm{AVF}=$ arteriovenous fistula; $E S D R=$ end stage renal disease; $\mathrm{SD}=$ standard deviation.

\section{Discussion}

The study results suggest that the SISC-AVF had a statistically significant positive effect, since patients in the IG exhibited better post-intervention self-care behaviors with
AVF than those in the CG. Very few quantitative studies are available in the literature assessing self-care behaviors with $\mathrm{AVF}$ and most analyze the level of knowledge of self-care with the AVF. The majority assesses the frequency of such behaviors (Ozen et al., 2017; Sousa et al., 2017; Yang et al., 
Table 2. Scale and Sub-Scales Descriptive Measures.

\begin{tabular}{|c|c|c|c|c|c|c|c|c|}
\hline & \multicolumn{4}{|c|}{ Pre-intervention } & \multicolumn{4}{|c|}{ Post-intervention } \\
\hline & Overall & CG & IG & $p$-value & Overall & CG & IG & $p$-value \\
\hline \multicolumn{9}{|l|}{ Overall scale } \\
\hline Mean $(S D)$ & $78.0(12.1)$ & $80.1(11.3)$ & $75.8(12.6)$ & .078 & $85.4(9.8)$ & $79.2(8.1)$ & $91.4(7.4)$ & $<.001$ \\
\hline Minimum & 34.4 & 42.2 & 34.4 & & 59.4 & 59.4 & 68.8 & \\
\hline Maximum & 95.3 & 95.3 & 95.3 & & 100.0 & 93.8 & 100.0 & \\
\hline First quartile & 71.1 & 76.6 & 67.6 & & 78.1 & 73.4 & 87.9 & \\
\hline Median & 79.7 & 81.3 & 77.4 & & 87.5 & 81.3 & 93.0 & \\
\hline Third quartile & 87.5 & 89.1 & 84.0 & & 93.8 & 84.4 & 96.9 & \\
\hline \multicolumn{9}{|c|}{ Management of signs and symptoms sub-scale } \\
\hline Mean $(S D)$ & $83.5(16.8)$ & $89.6(13.3)$ & $77.5(17.8)$ & .0002 & $92.3(9.3)$ & $90.1(8.9)$ & $94.4(9.3)$ & .004 \\
\hline Minimum & 16.7 & 37.5 & 16.7 & & 58.3 & 62.5 & 58.3 & \\
\hline Maximum & 100.0 & 100.0 & 100.0 & & 100.0 & 100.0 & 100.0 & \\
\hline First quartile & 75.0 & 87.5 & 66.7 & & 87.5 & 83.3 & 91.7 & \\
\hline Median & 87.5 & 91.7 & 79.2 & & 95.8 & 91.7 & 100.0 & \\
\hline Third quartile & 97.9 & 100.0 & 90.7 & & 100.0 & 100.0 & 100.0 & \\
\hline \multicolumn{9}{|c|}{ Prevention of complications sub-scale } \\
\hline Mean $(S D)$ & $74.6(13.6)$ & $74.4(13.9)$ & $74.8(13.5)$ & .967 & $81.2(12.5)$ & $72.7(10.4)$ & $89.5(7.9)$ & $<.001$ \\
\hline Minimum & 42.5 & 45.0 & 42.5 & & 50.0 & 50.0 & 70.0 & \\
\hline Maximum & 100.0 & 100.0 & 97.5 & & 100.0 & 95.0 & 100.0 & \\
\hline First quartile & 65.0 & 70.0 & 65.0 & & 72.5 & 62.5 & 83.1 & \\
\hline Median & 75.0 & 75.0 & 75.0 & & 82.5 & 75.0 & 92.5 & \\
\hline Third quartile & 85.0 & 85.0 & 86.9 & & 92.5 & 80.0 & 95.0 & \\
\hline
\end{tabular}

Note. $\mathrm{CG}=$ control group; IG = intervention group; $S D=$ standard deviation.

2019) but none of them discusses the methods used to teach patients. Our study assessed the effect of a structured intervention on the development of HD patients' self-care behaviors with AVF.

In this study, patients subject to the SISC-AVF exhibited an increase in the average overall frequency of self-care behaviors with AVF (75.8\%-91.4\%, $p<.001)$, as well as in both self-care subscales: $77.5 \%$ to $94.4 \%(p<.001)$ and $74.8 \%$ to $89.5 \%(p<.001)$ for the management of signs and symptoms subscale and for the prevention of complications subscale respectively (Table 3 ). On the contrary, the frequency remained approximately constant for patients in the CG $(p=.437, p=.561$ and $p=.722$, respectively, Table 3$)$.

Prior to the intervention, the difference between the groups' average self-care is not significant concerning both the overall scale $(p=.078)$ and the prevention of complications subscale $(p=.967)$ (Table 2$)$. On the contrary, such difference is significant concerning the management of signs and symptoms subscale with a larger average self-care in the CG than in the IG (89.6\% and $77.5 \%$, respectively, $p=.0002)$. After the intervention, IG patients' average self-care is higher concerning the overall scale and both subscales. These findings may mean that, regardless of demographic or clinical characteristics, patients had similar levels of self-care behaviors before the intervention (with the exception of the management of signs and symptoms), implying that self-care was not affected by such baseline characteristics. We could not
Table 3. Pre- and Post-Intervention Comparison for Each SelfCare Group.

\begin{tabular}{lr}
\hline & p-value \\
\hline CG & .437 \\
Overall scale & .561 \\
Management of signs and symptoms sub-scale & .722 \\
Prevention of complications sub-scale & \\
IG & $<.001$ \\
Overall scale & $<.001$ \\
Management of signs and symptoms sub-scale & $<.001$ \\
\hline
\end{tabular}

Note. $\mathrm{CG}=$ control group; IG = intervention group .

find any article or study in the literature assessing the effect of an intervention on self-care with AVF.

The increase in self-care after the intervention appears to be due to the SISC-AVF. In fact, unlike CG patients, whose average self-care behaviors remained constant, IG patients exhibited an increase in both the overall scale and the two subscales $(p<.001$ in the three cases, Table 3$)$ which means that the intervention affected all self-care behaviors and was then successful from every point of view.

In a study of 71 HD patients, Alsaqri et al. (2019) reported that the average scores of knowledge on self-care with AVF concerning infection prevention and concerning identification 
of the fistula's function increased from 2.0 to $2.3(p=.000)$ and from 2.0 to $2.7(p=.000)$ respectively after the implementation of the instructional module on AVF care. Therefore, the strategy used (educational group session) led to an improvement of the knowledge on self-care with AVF. In our study, a similar educational group session was provided (theoretical educational strategy) and a practical educational strategy was added. We believe that the introduction of the practical part in the SISC-AVF enabled patients to understand and develop the appropriate skills required to identify potentially problematic situations.

Research on HD patients' self-care behaviors with AVF is scarce but even less is available concerning the assessment of the effect of an intervention on the development of such behaviors. The literature shows the positive effect of structured nursing interventions in patients with inflammatory bowel disease (Tu et al., 2015), in patients at risk of anaphylaxis (Brockow et al., 2015) and on the modification of risk factors in patients with coronary heart disease (Fernandez et al., 2007). We are not aware of any studies assessing strategies with the purpose of enabling ESRD patients in HD to develop self-care behaviors with AVF. However, the need for interventions or programs specifically designed to enable ESRD patients to perform self-care behaviors with AVF can be found in the literature (Sousa et al., 2014). Replication of our study with the same methodology in other regions or countries is required in order to assess the effectiveness of the SISC-AVF and its success or failure. We think that testing other strategies is very important, especially those using a technological approach such as video devices or computer apps. Patient-to-patient education or an exclusively theoretical strategy are other possible alternatives.

Further research on this issue is required, possibly involving randomized control trials in order to confirm the effectiveness of each single intervention or of the combination of different interventions. Such studies can help designing educational programs whose interventions are adjusted to the patients' characteristics, that is, more than one sort of intervention may be appropriate in the implementation of such programs in the dialysis units, depending on the patients' individual characteristics.

Patients subject to intervention were able to improve their self-care behaviors and consequently they have become more careful in the identification of possible problems with the AVF. In fact, no cases of infection and associated thrombosis in the vascular access were found in the IG. This absence of complications needs to be explored in future studies, namely in order to assess the impact/relationship of self-care behaviors on the reduction and identification of AVF complications.

The same researcher assessed patients for eligibility and conducted the intervention process which might have increased the risk of bias and may be a possible shortcoming of our study. Another possible limitation was the study time span that prevented the analysis of the impact of self-care behaviors on AVF complications. The small group sizes (41 and 48 patients in the CG and IG, respectively) and the sampling method can also be considered a weakness. Nevertheless, this study should be considered as a first step for the identification of possible interventions with the purpose of improving the development of self-care behaviors with AVF.

\section{Conclusion}

The purpose of this research is to contribute to the identification of interventions leading to the development and improvement of self-care behaviors with the arteriovenous fistula based on a sample of Portuguese adults with chronic renal disease on HD. The results suggest that the SISC-AVF has a statistically significant and positive effect. Further experiments should be conducted in order to assess whether this intervention yields the same effect on other populations. Moreover, testing the effect of other interventions on the development and improvement of self-care behaviors is required in the future.

\section{Authors' Contributions}

Study conception and design: CNS, ARCP, CMCBP. Intellectual contribution and consultation: VFFD, CSSM, AGN, OMPLR, NO, LHS. Data collection: CNS, ARCP. Data analysis and interpretation: CNS, ARCP, PT. Drafting of manuscript: CNS, ARCP, VFFD, CSSM, AGN, NO, LHS. Critical revision: CMCBP, PT, OMPLR.

\section{Declaration of Conflicting Interests}

The author(s) declared no potential conflicts of interest with respect to the research, authorship, and/or publication of this article.

\section{Funding}

The author(s) received no financial support for the research, authorship, and/or publication of this article.

\section{Ethical Approval}

This study was prospectively registered in the United States of America Clinical Trials Registry Platform with identifier number: NCT03830658. The study started after approval by the institutions' ethics committees (Hospital Divino Espirito Santo ethics committee, number 0014HDES).

\section{ORCID iD}

Clemente Neves Sousa (iD https://orcid.org/0000-0003-2654-0497

\section{Supplemental Material}

Supplemental material for this article is available online.

\section{References}

Alsaqri, S., Edison, J., Alshammari, S., \& Ahmad, H. (2019). The effectiveness of instructional module on self-care practices of arteriovenous fistula among hemodialysis patients at Hail region, Saudi Arabia. International Journal of Advanced and Applied Sciences, 6(2), 87-93. 
Apóstolo, J., Paiva, D., Silva, R., Santos, E., \& Schultz, T. (2018). Adaptation and validation into Portuguese language of the six-item cognitive impairment test (6CIT). Aging \& Mental Health, 22(9), 1190-1195.

Brockow, K., Schallmayer, S., Beyer, K., Biedermann, T., Fischer, J., Gebert, N., Grosber, M., Jakob, T., Klimek, L., Kugler, C., Lange, L., Pfaar, O., Przybilla, B., Rietschel, E., Rueff, F., Schnadt, S., Szczepanski, R., Worm, M., Kupfer, J., . . . Ring, J. (2015). Effects of a structured educational intervention on knowledge and emergency management in patients at risk for anaphylaxis. Allergy, 70(2), 227-235.

Clementi, A., Coppolino, G., Provenzano, M., Granata, A., \& Battaglia, G. (2020). The holistic vision of the patient with chronic kidney disease in an universalistic health care system. Therapeutic Apheresis and Dialysis. Advance online publication. https://doi.org/10.1111/1744-9987.13556

Coelho, A., Sá, H., Diniz, J., \& Dussault, G. (2014). The integrated management for renal replacement therapy in Portugal. Hemodialysis International, 18(1), 175-184.

Enrica, F., \& Manjula Kurella, T. (2016). Epidemiology and public health concerns of chronic kidney disease in older adults. Advances in Chronic Kidney Disease, 23(1), 8-11.

Fernandez, R., Griffiths, R., Everett, B., Davidson, P., Salamonson, Y., \& Andrew, S. (2007). Effectiveness of brief structured interventions on risk factor modification for patients with coronary heart disease: A systematic review. International Journal of Evidence-Based Healthcare, 5(4), 370-405.

Ibeas, J., Roca-Tey, R., Vallespín, J., Moreno, T., Moñux, G., MartíMonrós, A., Del Pozo, J. L., Gruss, E., Ramírez de, Arellano, M., Fontseré, N., Arenas, M. D., Merino, J. L., GarcíaRevillo, J., Caro, P., López-Espada, C., Giménez-Gaibar, A., Fernández-Lucas, M., Valdés, P. Fernández-Quesada, F., . . . por el Grupo Español Multidisciplinar del Acceso Vascular (GEMAV). (2017). Spanish Clinical Guidelines on Vascular Access for Haemodialysis. Nefrologia, 37(Suppl. 1), 1-191.

Kitchie, S. (2016). Determinants of learning. In S. Bastable, Nurse as educator: Principles of teaching and learning for nursing practice (pp. 113-158). Jones And Bartlett Learning.

Kukita, K., Ohira, S., Amano, I., Naito, H., Azuma, N., Ikeda, K., Kanno, Y., Satou, T., Sakai, S., Sugimoto, T., Takemoto, Y., Haruguchi, H., Minakuchi, J., Miyata, A., Murotani, N., Hirakata, H., Tomo, T., Akizawa, T., \& Vascular Access Construction and Repair for Chronic Hemodialysis Guideline Working Group, Japanese Society for Dialysis Therapy. (2015). 2011 Update Japanese society for dialysis therapy guidelines of vascular access construction and repair for chronic hemodialysis. Therapeutic Apheresis and Dialysis, 19(Suppl. 1), 1-39.

Moist, L., Lee, T., Lok, C., Al-Jaishi, A., Xi, W., Campbell, V., Graham, J., Wilson, B., \& Vachharajani, T. J. (2013). Education in vascular access. Seminars in Dialysis, 26(2), 148-153.

NKF-K/DOQI. (2006). K/DOQI clinical practice guidelines in vascular access: 2006 update. American Journal of Kidney Diseases, 48, S227-S364.

Ozen, N., Tosun, N., Cinar, F., Bagcivan, G., Yilmaz, M., Askin, D., Mut, D., Ozen, V., Yenicesu, M., \& Zajm, E. (2017). Investigation of the knowledge and attitudes of patients who are undergoing hemodialysis treatment regarding their arteriovenous fistula. The Journal of Vascular Access, 18(1), 64-68.

Pessoa, N., Lima, L., Santos, G., Frazão, C., Sousa, C., \& Ramos, V. (2020). Self-care actions for the maintenance of the arteriovenous fistula: An integrative review. International Journal of Nursing Sciences, 7(3), 369-377.

Pessoa, N., \& Linhares, F. (2015). Hemodialysis patients with arteriovenous fistula: Knowledge, attitude and practice. Escola Anna Nery - Revista de Enfermagem, 19(1), 73-79.

Schmidli, J., Widmer, M., Basile, C., de Donato, G., Gallieni, M., Gibbons, C., Haage, P., Hamilton, G., Hedin, U., Kamper, L., Lazarides, M. K., Lindsey, B., Mestres, G., Pegoraro, M., Roy, J., Setacci, C., Shemesh, D., Tordoir, J. H. M., \& van Loon, M. (2018). Editor's choice - vascular access: 2018 clinical practice guidelines of the European Society for Vascular Surgery (ESVS). European Journal of Vascular and Endovascular Surgery, 55(6), 757-818.

Sousa, C. (2012). Caring for the person arteriovenous fistula: Model for continuous improvement. Revista Portuguesa de Saúde Pública, 30(1), 11-17.

Sousa, C. N., Apóstolo, J. L., Figueiredo, M. H., Martins, M. M., \& Dias, V. F. (2014). Interventions to promote self-care of people with arteriovenous fistula. Journal of Clinical Nursing, 23(13-14), 1796-1802.

Sousa, C., Apóstolo, J., Figueiredo, M., Dias, V., Teles, P., \& Martins, M. (2015). Construction and validation of a scale of assessment of self-care behaviors with arteriovenous fistula in hemodialysis. Hemodialysis International, 19(2), 306-313.

Sousa, C., Marujo, P., Teles, P., Lira, M., Dias, V., \& Novais, M. (2020). Self-care behavior profiles with arteriovenous fistula in hemodialysis patients. Clinical Nursing Research, 29(6), 363-367.

Sousa, C., Marujo, P., Teles, P., Lira, M., \& Novais, M. (2017). Self-Care on hemodialysis: Behaviors with the arteriovenous fistula. Therapeutic Apheresis and Dialysis, 21(2), 195-199.

Teixeira, G., Almeida, P., Sousa, C., Teles, P., De Sousa, P., Loureiro, L., Teixeira, S., Rego, D., Almeida, R., \& de Matos, A. N. (2017). Arteriovenous access banding revisited. The Journal of Vascular Access, 18(3), 225-231.

Tordoir, J., Canaud, B., Haage, P., Konner, K., Basci, A., Fouque, D., Kooman, J., Martin-Malo, A., Pedrini, L., Pizzarelli, F., Tattersall, J., Vennegoor, M., Wanner, C., ter Wee, P., \& Vanholder, R. (2007). EBPG on vascular access. Nephrology Dialysis Transplantation, 22(Suppl. 2), ii88-ii117.

Trask, M., Marchuk, S., Rozon, C., Puyat, J., Costantini, L., Mackay, M., \& Ocampo, L. (2016). The evaluation of an orientation program of selfcare abilities for patients on hemodialysis. Nephrology Nursing Journal, 43(6), 501-534.

Tu, W., Xu, G., \& Du, S. (2015). Structure and content components of self-management interventions that improve health-related quality of life in people with inflammatory bowel disease: A systematic review, meta-analysis and meta-regression. Journal of Clinical Nursing, 24, 2695-2709.

Wingard, R. (2005). Patient education and the nursing process: Meeting the patient's needs. Nephrology Nursing Journal, $32(2), 211-214$.

Yang, M., Zhao, H., Ding, X., Zhu, G., Yang, Z., Ding, L., Yang, X. H., Zhao, Y., Chen, L., Yang, R. M., Fang, J., \& Sousa, C. N. (2019). Self-care behavior of hemodialysis patients with arteriovenous fistula in China: A multicenter, cross-sectional study. Therapeutic Apheresis and Dialysis, 23(2), 167-172.

\section{Author Biographies}

Clemente Neves Sousa, PhD, RN, adjunct professor at Nursing School of Porto, Porto, Portugal. 
Ana Rita Cabral Paquete, is Master in Medical Surgical Nursing, RN, nephrology nurse at Hospital Divino Espirito Santo, Azores, Portugal.

Paulo Teles, PhD, professor at School of Economics, University of Porto, Portugal.

Cristina Maria Correia Barroso Pinto, $\mathrm{PhD}, \mathrm{RN}$, adjunct professor at Nursing School of Porto, Porto, Portugal.

Vanessa Filipa Ferreira Dias, PhD student, MPH, RM, nurse at Unidade de Saúde Familiar St. André de Canidelo, Vila Nova de Gaia, Porto.
Olga Maria Pimenta Lopes Ribeiro, $\mathrm{PhD}, \mathrm{RN}$, adjunct professor at Nursing School of Porto, Porto, Portugal.

Carlene Souza Silva Manzini, PhD, RN, São Carlos Federal University (UFSCar), São Carlos, Brazil.

Andressa Garcia Nicole, PhD student, RN, Espírito Santo Federal University, Espírito Santo, Brazil.

Nurten Ozen, PhD, RN, assistant professor at Demiroglu Bilim University in Istanbul, Turkey.

Lara Helk de Souza, PhD, RN, professor at Faculdade de Medicina de São José do Rio Preto (FAMERP), Brazil. 